\title{
INTRODUCCIÓN AL PROTOCOLO ECLESIÁSTICO DE JUAN SÁNCHEZ, NOTARIO APOSTÓLICO DE MURCIA, SIGLO XV
}

Francisco-Reyes Marsilla de Pascual

\section{RESUMEN}

El presente trabajo es el inicio del estudio paleográfico y diplomático del Protocolo o Libro de Notas de Juan Sánchez de Santisteban, notario apostólico de la Audiencia episcopal de Cartagena; único ejemplar existente en el archivo de la Catedral de Murcia. A través de sus «Notas» podemos conocer la estructura y desarrollo de la Audiencia episcopal cartaginense a mediados de la centuria del XV: oficiales y notarios, tipología documental y actuaciones jurídicas diversas.

This article is to initiate the study paleographic and diplomatic of the Protocol Book or «Libro de Notas» of Juan Sanchez de Santisteban, notary by apostolic authority in the Chancery Episcopal Court of Cartagena, existins in the Record Office of Cathedral of Murcia, most of them unpublished. Throuhg him we can to know the structure and organization Chancery Episcopal Court during 15th century: Officials and notarys, chancery formulary and rules, chancery documents...

PALARAS CLAVE: Notariado eclesiástico, Diplomática. 


\section{INTRODUCCIÓN}

El Protocolo o Libro de registros que presentamos es el vestigio más importante, y probablemente el único, en su género, del Archivo Catedral de Murcia, que nos ha llegado de las minutas o notas de la documentación expedida por la audiencia episcopal murciana en la segunda mitad de la centuria del XV.

Pertenece a uno de los notarios apostólicos de la audiencia episcopal, Juan Sánchez de San Esteban, arcipreste de Gormaz, que durante un período de trece años aproximadamente - de 1459 a 1472 - actuó como tal, llegando a ocupar el cargo de secretario del obispo don Diego de Comontes hacia 1459 y su continuación en el mismo con el obispo don Lope de Rivas hacia 1474'.

Legado éste que, a pesar de los incidentes y avatares por los que ha pasado la historia del mencionado archivo catedralicio desde 1651, hoy día conservamos gracias a la labor de catalogación y espurgo hecha por el doctoral Juan-Antonio de la Riva en $1802^{2}$. Él mismo declara, refiriéndose a lo acontecido en 1651: «...la riada de sant Calixto entro en dicha sacristia y subio media vara sobre la caxoneria, se entarquinaron muchos papeles, que por eso y ser de letra antigua se creian ilegibles y estaban abandonados... $)^{3}$. La fortuna hizo que el protocolo que ahora nos ocupa estuviera entre éstos, dado las grandes manchas de humedad y los restos de limo que presenta, y corroborado por el mismo doctoral en una hoja introductoria: «En este protocolo se registran algunas notas tocantes al cabildo, por lo qual y por otras notizias que arrojan semejantes documentos antiguos debe conservarse».

Como fuente histórica y jurídica es mucho lo que este protocolo puede aportar al mejor conocimiento, no sólo de los más variados aspectos de la institución eclesiástica bajomedieval murciana, sino también del funcionamiento y desarrollo juridico-administrativo de la misma, su escribanía y audiencia episcopal.

Así pues, dado la amplitud de temas que se podrían tratar y las limitaciones de espacio de que disponemos, nos limitaremos a ofrecer un comentario codicológico y diplomático de dicho protocolo, así como un esbozo de los oficios de la escribanía y audiencia, centrándonos en la figura del notario.

1 A.C.M. ROXAS Y CONTRERAS, D. de: «Diferentes instrumentos, bulas y otros documentos pertenecientes a la dignidad episcopal». Cód. 940, f. 125v-126r.

Ibd. «Tribunal eclesiástico de Murcia», Año de 1459. Cód. 202.

lbd. «Protocolo o Notas de Juan Sánchez de Santisteuan», Cód.B-2, f. 123r-123v.

2 A.C.M. Actas Capitulares de 1802. Cód. 85, f.78v-79v., «Propuesta del señor doctoral de la Riva sobre el arreglo del archivo».

3 A.C.M. Actas Capitulares de 1455 a 1494. Cód. B-I, f.1r-7v.

lbd. Cód.B-2. cit. f.1r. 


\section{PERSONAL DE LA ESCRIBANÍA Y AUDIENCIA: EL NOTARIO}

Desde la restauración de la Diócesis Cartaginense por Inocencio IV y la organización de su cabildo por el obispo don Pedro Gallego en 1250, hasta el traslado de su capitalidad de Cartagena a Murcia en 1291, no tenemos testimonio escrito alguno que evidencie la presencia de escribanos o notarios eclesiásticos ${ }^{4}$ actuando como tales. Será en 1309 cuando Fernando IV por real provisión y a instancias del obispo don Martín Martínez, dote al obispado e iglesia de Cartagena de un notario público de la ciudad - Bondugo Flores- para que «...diese fe, bien et lealmente de las afruentas et de las protestaciones et de las otras escripturas que antel pasaren et fueren fechas por el dicho obispo et por la su yglesia... "s. Es a partir de este momento cuando podemos presenciar el inicio de las funciones notariales en el seno de la Iglesia de Cartagena; desempeñadas, en un primer momento, por los notarios públicos de la ciudad, y más adelante y a lo largo de toda esta centuria, compartida con los notarios apostólicos o episcopales y los de la iglesia propiamente dichos.

A estos últimos -eclesiásticos la mayoría- la «auctoritas notariae» les era conferida por el obispo — canciller nato y presidente de la audiencia - o, como es nuestro caso, su provisor o vicario general en su nombre, no sin antes haber sido examinados y jurado fidelidad y obediencia al obispo, así como el fiel cumplimiento de todo lo dispuesto por la legislacion diocesana?.

Hacia la primera mitad del XIV, y más concretamente en 1330, la Diócesis contará con una notaría episcopal que atendería conjuntamente las necesidades del cabildo y la iglesia en general ${ }^{8}$. Toda la documentación de ambos organismos quedaba registrada en los llamados Libros blancos, donde se asentaba todo tipo de

4 Toda la documentación de este periodo la suscriben notarios reales y notarios públicos de la ciudad. Vid. TORRES FONTES, J.: «El Obispado de Cartagena en el siglo XIll», Hispania, 53 (1953), pp. 546-580 (Apéndice Documental). Los términos "escribano" y unotario» se funden en una misma persona.

5 TORRES FONTES, J.: "Colección de Documentos para la Historia del Reino de Murcia», Vol. V. Documentos de Fernando IV, C.S.I.C, Murcia, 1980. Doc. ${ }^{\circ}$ LXXXV, pp. 93-94.

6 GARCÍA DÍAZ, I.: «Colección de Documentos...», Vol. IV. Documentos siglo XIV. Archivo Catedral. C.S.I.C., Murcia, 1989. Aparecen 49 notarios los cuales se suscriben: 6 como Notarios Apostólicos de la Iglesia, 8 como Notarios Públicos y de la Iglesia, y 35 como Notarios Públicos de la ciudad.

7 A.C.M. «Synodales de la Yglesia de Carthagena», Cód. s/n, «De officio Notariorum», Cap. 1: "Que los notarios sean examinados y juren antes que sean admitidos al officio.»

8 Es en 1330 cuando, por vez primera, suscribe un documento un notario apostólico, Berenguer Arnalt, perteneciente a la escribanía episcopal y escribano «...en todo el obispado.». Vid. GARCÍA DÍAZ, I.: Ob.cit. Doc n 12, pp.19-20. p. 478.

Cfr. CÁRCEL ORTI, M.: «El documento episcopal». B.S.C.C.. tomo LVIII, Castellón, 1982. 
escrituras, censos, testamentos, arrendamientos, ordenanzas, etc. ${ }^{9}$ Esta situación permanece hasta 1455 - año que comienzan a redactarse los libros de Actas Capitulares o «Libro del secreto de los fechos de negozios que se fazen en el dicho cabildo" - en que la institución capitular parece posee ya su propia escribanía, separada de la episcopal. Ésta tendrá facultad para nombrar sus oficiales -llamados «secretarios del secreto" - escogidos de entre cualquiera de los capitulares que estuviere doctorado o licenciado en Leyes - generalmente canónigos y racioneros- teniendo como misión «el asentar las cosas e fechos que pasasen en cabildo ${ }^{10}$. Junto a ellos y a partir de 30 de julio de 1456, aparece el oficio de «secretario capitular de instrumentos» que, procedente de la notaría y audiencia episcopal, su cometido será «...este a los dias de los cabildos e que faga los autos e ynstrumentos que se ordenaren e fizieren en los cabildos de los sennores...»"

Así pues es a partir de la segunda mitad de la decimoquinta centuria cuando podemos establecer una separación casi autónoma entre ambas notarías, la episcopal y la capitular ${ }^{12}$.

Al frente de la notaría episcopal encontramos, durante el siglo XV, a 24 notarios apostólicos, de los cuales cuatro, a mediados de la centuria, se integrarían como componentes importantes dentro de la misma: Pedro Martínez de Chinchilla, Pedro de Pina, Pedro González de Vizcaya y Juan Sánchez de San Esteban. Éstos, a diferencia de los 20 notarios restantes, se suscriben como: «...notario publico por las abtoridades apostolica e real e escriuano de la eglesia e abdiencia e juzgado episcopal de Cartajena...»; añadiendo, en el caso de Juan Sánchez de San Esteban, el oficio de «...secretario del dicho sennor obispo...»" El subtítulo de escribanos «...de la abdiençia e juzgado...» creemos identifica a éstos como integrantes de un cuerpo de «notarios mayores», dentro de la notaría

9 A.C.M. Libro 1 de Testamentos, donaciones, fundaciones y censos y otras escrituras. Cód. 258.

Ibd. Libro 11 de Testamentos, donaciones.... Cód. 259.

Ibd. Libro 111 de Testamentos, donaciones... Cód. 260.

10 A.C.M. Cód. B-1, cit. Sesiones capitulares de 21 de sept. 1459, 19 de nov. 1462, 15 de enero 1465, 24 de dic. 1467. (Nombramientos de secretarios capitulares del secreto).

11 A.C.M. Cód. B-1, cit. f.3r.

12 Aunque ya se especifica el cometido y funciones de una y otra notarías, la episcopal tendrá supremacía sobre la capitular en los asuntos relevantes y en aquellos que competan a ambos organismos, obispo y cabildo.

13 A.C.M. Cód. B-1, cit. f.3r. Ibd. Cód. 202, cit. Ibd. Legajo s/n: «Escriptura de concordia entre obispo y cabildo sobre la tenencia de la Torre de Alguazas» 1451. Ibd. Legajo s/n: «Escriptura de concordia entre abispo y cabildo y el señor de la villa de Ceuti sobre el acequia de Alguazas» 1486 . Ibd. Legajo s/n: «Sentenzia de juezes arbitros sobre terminos de la villa de Alguazas y Ricote» 1468. 
episcopal, y cuyo cometido sería el ayudar al provisor en sus funciones como canciller".

\section{LA AUDIENCIA}

A pesar de las limitaciones diplomáticas que el presente protocolo nos ofrece -etcéteras, notas- podemos vislumbrar por su secuencia cronológica continua de días, meses y años, una visión clara del funcionamiento y estructura de la audiencia episcopal del XV.

El lugar en que ésta tiene lugar es la capilla de San Juan de la Claustra de la catedral, y en ocasiones, en una sala del palacio del obispo, habilitada para tales menesteres. Se celebrará audiencia los lunes, miércoles y viernes en sesión ordinaria, y martes, jueves y sábados en sesión extraordinaria.

Los oficiales que integran la misma son: en primer lugar, el Provisor, juez supremo que la preside, sustituido en ocasiones por el vicario, un teniente de vicario o el maestrescuela; seguido a este se encuentran los Notarios, distinguiendo dos categorías: Notarios Mayores, encargados de asistir al obispo y provisor siempre que fuese necesario para el buen despacho de los negocios; y los Notarios Menores, cuya misión es, entre otras, la redacción de la documentación y el ejercicio de la procuraduría en los pleitos que se traten ${ }^{15}$; a continuación se encuentra el oficio de Fiscal, cuya misión es acusar y denunciar los delitos de los inculpados. Éste debe ser necesariamente sacerdote, y su habilitación y nombramiento como tal depende de la autoridad del obispo ${ }^{16}$. Junto a éstos encontramos la figura u oficio de Receptor, encargado de negociar los asuntos de la audiencia fuera de la ciudad, y el Nuneio, cuya obligación es la de citar a las personas que los notarios les ordenasen, no sólo en la ciudad, sino en todo el obispado. Estos últimos reciben también el nombre de «cursor» ${ }^{17}$.

14 A.C.M. «Synodales de la Yglesia de Carthagena», cit., «De officio notariorum», Cap. IV: "Que los processos y demas negozios se repartan entre los notarios por el prouisor». Vid. CÁRCEL ORTÍ, M.: «El documento episcopal», Ob. cit., p. 475. «El notarius domini episcopi» desempeñará las funciones del canciller y dictará o escribirá las minutas». Ibd. CÁRCEL ORTf: “Un Registro de colaciones de la Curia Episcopal Valentina (1349-1350)», B.S.C.C., Tomo LXVII, Castellón, 1991, pp. 184 a 187.

15 A.C.M. «Synodales...», cit. «De foro Competenti», Cap. VII.

16 Ibd. "Synodales...», cit. «De officio promotoris fiscalis».

lbd. Códice B-2, cit., f.223v. Nombramiento de un fiscal por el obispo don Lope de Rivas en 1475.

17 Ibd. «Synodales...», cit. «De officio nuntii». 


\section{EL PROTOCOLO: ESTUDIO CODICOLÓGICO}

El presente protocolo o Libro de Notas, objeto de nuestro estudio, se encuentra en el Archivo Catedral de Murcia, recogido en una caja de cartón, registrado con la signatura B-2 y clasificado, erróneamente, en Catálogo-inventario como «Actas Capitulares» ${ }^{18}$.

Anteriormente éste debió encontrarse depositado en una de las cuatro dependencias que la iglesia-catedral tuvo habilitadas como archivo: el «secretario» o eapillita interior de la sacristía, bajo la torre, hasta 1650; la «sala capitular»o capilla de San Juan de la Claustra, hasta 1786; en «Contaduría»; o en una estancia que las fuentes consultadas nos describen como «...vna pieza alta, donde además de estar expuestos (Codices y papeles varios) a las inundaciones del cielo y sumo calor del estio que los consume, igualmente que la polilla, y no tienen la seguridad correspondiente... $\gg^{19}$ hasta 1802.

El volumen, tal como ha llegado a nosotros, consta de un bloque de folios manuscritos - recto y vuelto- reunidos en once cuadernillos cosidos de $310 \mathrm{~mm}$. x $220 \mathrm{~mm}$. en los que se presentan algunas lagunas - la intitulación, suscrita y signada del notario, al inicio y final del libro; cronológicas —dada la irregular composición de los cuadernos ${ }^{20}$. Cubriendo su parte frontal, a modo de tapa 0 cubierta, presenta un trozo de pergamino de igual dimensión que los folios en cuyo recto leemos: «Al notario Santisteuan». Seguida a ésta aparecen dos folios de calidad inferior al resto, en que a modo de intitulación, en el segundo de ellos, leemos: «PROTOCOLO O NOTAS DE JUAN SANCHEZ DE SANTISTEVAN, NOTARIO PUBLICO, como resulta de su firma, quaderno 6 por medium, que es la unica que aqui se encuentra. Desde 30 de septiembre de 1468 hasta 13 de

18 El Libro de A.C. propiamente dicho es el Cód. B-1 abarcando un período de 1455 a 1494. El error - ya subsanado - responde a una posible catalogación de los fondos del archivo catedral, a comienzos de este siglo, en que a varios cuadernos, separados y perdidos, del protocolo se les clasificó como «Borradores de Autos Capitulares».

19 Vid. Nota $n^{\circ} 2$.

20 Contienen cada uno de los cuadernos los folios siguientes:

1 드 Cuaderno: f. 1-5.

$2^{\circ}$ Cuaderno: f. 6-15.

3or Cuademo: f. 16-66.

$4^{\circ}$ Cuaderno: f. 67-92.

$5^{\circ}$ Cuaderno: f. 93-104.

$6^{\circ}$ Cuaderno: f. 105-137.

$7^{\circ}$ Cuaderno: f. 138-155.

$8^{\circ}$ Cuaderno: f. 156-169.

$9^{\circ}$ Cuaderno: f. 170-179.

10 Cuaderno: f. 180-199.

$11^{\circ}$ Cuaderno: f. 200-213. 
noviembre de 1473". Tanto la cubierta y la introducción responden a la efectuada por el doctoral de la Riva en $1802^{21}$.

A estos once cuadernos a que hacemos referencia, últimamente añadimos un cuaderno más - de $310 \mathrm{~mm}$. x $220 \mathrm{~mm}$., compuesto de 48 folios manuscritos en su recto y vuelto- y cuatro folios sueltos de las mismas características, encontrados en otros apartados del mencionado archivo catedral, que subsanan de alguna manera las lagunas cronológicas, sobre todo. Así pues, al presente, conforman dicho volumen 12 cuadernos con un total de 269 folios, siendo muy irregular aún la composición foliar por cuaderno, oscilando entre los 5 del primero y los $48 \mathrm{del}$ doceavo"2.

El soporte material es el papel, de textura gruesa y superficie rugosa. No se observan marcas de agua en todos los folios, aunque, intercaladamente y sin un orden específico, encontramos cuatro tipos de filigrana distintas: una perteneciente a la familia de las balanzas, adaptando una posición central en el folio ${ }^{23}$; otra, de la familia de las coronas, de posición central, adoptando la forma recta e inverti$\mathrm{da}^{24}$; otra, de la familia de las tijeras, de posición central y lateral derecho, adoptando las formas recta e invertidaa ${ }^{25}$ y por último, otra de la familia de los animales, de posición central ${ }^{26}$.

Así mismo no se observa numeración alguna de folios ni indicio alguno que nos dé muestra de ello, a pesar del deterioro y las grandes manchas de humedad que presentan los margenes derechos de los mismos.

La caja de escritura presenta cierta homogeneidad en todos los folios, $250 \mathrm{~mm}$. x $180 \mathrm{~mm}$., aunque en ocasiones la amplitud de los márgenes es desigual, siendo el más generoso de espacio el lateral izquierdo $-50 \mathrm{~mm}$., reservado para las notaciones marginales - al que le sigue el margen superior -oscilando entre $40 \mathrm{~mm}$. y $30 \mathrm{~mm}$. - y el inferior es más reducido —oscila entre $30 \mathrm{~mm}$. y 20 $\mathrm{mm}$.- Las líneas de escritura quedan perfectamente alineadas por la izquierda,

21 Así lo demuestra el tipo de escritura, propia del XIX, el papel utilizado para ello y la rúbrica del doctoral de la Riva bajo el preámbulo introductorio.

22 Creemos que la composición foliar de cada cuaderno oscilarín de 10 a 20 pliegos doblados por mitad, según era usual en los protocolos castellanos del XV. Cfr. BONO HUERTA. J.: «Los Archivos Notariales». Ciuadernos de Archivos, 1. Junta de Andalucía. 1981, pp. 21-22.

23 Cfr. BRIQUET, C.M.: Les filigranes, New York, 1966. Tomo I, n 2.407. /b. Abellín Pérez, J.y J.: «Las filigranas del archivo municipal de Murcia». Miscelánea Medieval Murciana, VI, Murcia 1980, p. 138, ne 14-19.

24 Ibd. BRIQUET, C.M.: Ob.cit. Tomo 2, $n^{\circ} 4602-4605$.

Ibd. ABELLÁN PÉREZ, J. y J.: Ob.cit., p. 139, $\mathrm{n}^{\mathrm{m}} 66$ y 67.

25 Ibd. ABELLÁN PÉREZ. J. y J.: Ob.cit., p. 142, $n^{\omega 2} 168$.

26 Ibd. BRIQUET: Ob. cit. Tomo 1, $\pi^{\circ} 2845$.

Ibd. ABELLÁN PÉREZ: Ob. cit., p. 143, n 176-179. 
no así por la derecha El número de líneas no es uniforme, sino que varía en relación al asunto que se trate y al tamaño de la letra empleada por el amanuense.

Se observa la presencia de tres manos en la ejecución de los distintos asuntos documentados; una de éstas, creemos sea la del propio notario, Juan Sánchez, que aparece signando los dos únicos asuntos desarrollados in extenso en dicho protocolo $^{27}$; las otras dos corresponderán a los notarios menores, amanuenses, ayudantes del dicho notario, Juan Sánchez.

El tipo de escritura del presente protocolo es la típica gótica cursiva documental - de uso generalizado a partir del XVl en la documentación notarial ${ }^{28}$ - con predominio de la procesal sobre la cortesana. La primera se nos hace patente en la casi totalidad de lo escriturado, mientras la segunda aparece tan sólo en los asuntos, si no escritos, sí signados por el dicho notario Juan Sánchez. Escritura cursiva característica de escribano que ejecuta su obra sin condicionamientos especiales; arbitrariedad que se traduce en la abundancia de abreviaturas, escrituración incorrecta o incompleta de los nombres propios - sobre todo los referentes a judíos, musulmanes y genoveses ${ }^{29}-$ y en las frecuentes tachaduras, correcciones y cortes -espacios en blanco- que padece el texto.

Reservada para el epígrafe cronológico de comienzo de un año natural se utilizará la escritura gótica caligráfica o fracturada, con caracteres capitales.

La tinta utilizada oscila en su coloración de un ocre oscuro a un ocre amarillento.

\section{EL PROTOCOLO: ESTUDIO DIPLOMÁTICO}

El presente volumen, aunque realizado en los albores de la Edad Moderna — segunda mitad del siglo XV- responde, en gran medida, al modelo estructural de los protocolos notariales castellanos de la Alta Edad Media ${ }^{30}$.

Nos encontramos ante un Protocolo o Libro de Notas, propiamente dicho descrito por J. Bono como «un conjunto ordenado cronológicamente y en forma de libro, integrado por cuadernos sucesivos, en el que se asientan las notas o redacción primera de los negocios jurídicos, así como las anotaciones relativas a estas mismas notas que han sido formalizadas por un notario en un período de

27 A.C.M. Cód. B-2, f. 123r-123v. y 253r-253v.

28 MILlARES, J. A. y MANTECÓN, J.: Paleografía Hispanoamericana de los siglos XVI y XVIII, Vol. 1, Barcelona, 1975, pp. 41 y ss.

29 Son numerosas las abreviaturas de carácter jurídico: $R a=$ Rebeldía, fácilmente confundible con su homónima «recibía». Del mismo modo los nombres de personas y lugares no presentan cierta ecuanimidad en su forma escrita o abreviada.

30 Cfr. ALFONSO, X: Partidas, p. 3. 18. 24; BONO, J.: Ob. cir., pp. 17-18. 
tiempo determinado " ${ }^{31}$. Ahora bien, atendiendo al desdoblamiento que existe en la Edad Media entre «Libro de Notas» y «Registro» dentro del término generalizado de "Protocolo» ${ }^{32}$, creemos poder unificar ambos términos en el contenido del presente volumen objeto de estudio; dado que si por un lado son muy numerosas las llamadas «notas abreviadas» del otorgamiento documental —acusamientos de rebeldía, términos probatorios, citaciones a audiencia, etc.- , no son menos numerosos los llamados «registros», con redacción extensa, con suspensión de cláusulas - desarrollo de los etcéteras- y la dicción, en ocasiones, de la data implícita en la nota - otorgamientos de poder, cláusulas testamentarias, contratos de arrendamiento, testimonios o «dichos» de testigos, etc.-. Aspecto este último que obedece a lo establecido por la legislación diocesana de Cartagena en su ordenanza «DE OFFICIO NOTARIORUM": "Que los notarios no tomen en minuta poder ni dicho de testigo so pena de suspension de officio por tienpo de vn anno por la primera vez, y de priuazion por la segunda.» ${ }^{33}$.

Al mismo tiempo, integrados en el cuerpo documental de dicho volumen, encontramos dos «instrumentos» desarrollados in extenso, sin supresión de cláusulas y con suscripción y signo notarial —uno de ellos- que los clausura.

Esta heterogeneidad en la actuación documental nos lleva a pensar sea el presente protocolo eclesiástico un claro precedente de la conformación genérica del protocolo notarial a partir de la decimosexta centuria, donde «un único Libro de Notas, denominado universalmente Registro, será general para toda clase de negocios juridicos: Contratos, testamentos, apoderamientos, actuaciones judiciales, etc.» ${ }^{34}$.

La legislación diocesana recoge asimismo este término universal de «registro». La primera referencia la encontramos en el Capítulo XII de la ordenanza $« D E$ OFFICIO NOTARIORUM» donde se estipula: "Quando los notarios dieren alguna escriptura que vuiere passado ante ellos, dexen registro della en su poder firmado del nonbre de la parte o de otro por della, y guarden en esto todo lo que esta mandado a los escriuanos reales que hagan e cumplan so las penas que les estan inpuestas por las leyes destos reynos y tengan libros de registros cosidos por orden de años y abecedario ${ }^{35}$. La segunda mención o referencia la encontramos en el Capítulo XXIII de la misma ordenanza anterior: "Quando algun motario

\footnotetext{
31 BONO HUERTA, J.: «Los archivos....», p. 22.

32 lbd. pp. 22-23.

33 A.C.M. «Synodales de la Iglesia...» Ob. cit, «De officio notariorum», Cap. XV.

34 BONO, J.: Ob. cit., pp. 23-24.

35 A.C.M. «Synodales de la Iglesia de Carthagena». ob. cit. Cap. XII: "Que los notarios dexen registro firmado de la parte quando dieren alguma escriptura signada».
} 
muriere o fuere despedido, sus registros o escripturas se pongan a recaudo y se entrequen al que le succediere en el offizio." ${ }^{36}$.

A tenor de lo cual apreciamos una vez más esa heterogeneidad de la acción documental, englobando con el término registro, no sólo el conjunto de documentos en su primera fase textual de redacción, sino también los redactados en su segunda y tercera fase final textual -el instrumento o escritura-; el uso de la disyuntiva «o» en las fuentes, denota cierta ecuanimidad entre ambos términos.

Hechas estas consideraciones pasamos a describir la estructura y disposición de las notas-registros que conforman el protocolo eclesiástico que tratamos, donde se constata su simplicidad y reiteración.

La escrituración y desarrollo de éstas aparece dispuesta siguiendo un orden eminentemente cronológico, de extensión continuada y sin páginas en blanco. En primer lugar, se consigna el año natural ocupando un amplio espacio central en la caja de escritura - por lo general escriturado, otras abreviado en numerales romanos-; seguido éste y mediando un espacio en blanco -15 a $20 \mathrm{~mm}$.- se constata la data, a modo de epígrafe, generalmente expresando: el día de la semana, día del mes, el mes, el año y la persona o personas que ostentan el cargo de juez eclesiástico -Provisor y Vicario- y sustituyen a éstos en su ausencia -teniente de vicario y maestrescuela: «LUNES A DIEZ DIAS DE ENERO DE SETENTA E QUATRO ANTELL DICHO SENNOR PROUISOR».

Aunque en ocasiones y dentro de lo tratado en un mismo período de tiempo mes o año, se eluden algunos de estos elementos, bien porque se presupone de epigrafes anteriores, bien por descuido del amanuense que los redacta. Así los casos en que no se consigna el año: "MIERCOLES A XII DE ENERO ANTELL DICHO SENNOR PROUISOR»; o no figura la persona que preside la audiencia: "VIERNES A XIII DE ABRIL ANNO DE LXIX»; y ocasiones en que se antepone a la data crónica el lugar en que se desarrolla el acto documentado:

"MURCIA A XIIII DE FEBRERO DE LXXIIII ANTELL SENNOR TENYENTE ${ }^{37}$. A continuación, mediando un espacio en blanco correspondiente a una línea de escritura, se irán insertando por orden de recepción cada una de estas notas-registros referentes a los negocios jurídicos acaescidos ese día, dejando así mismo un espacio similar entre el final y comienzo de cada una de éstas.

El número de asentamientos por día variará, de dos a ocho en sesión ordinaria (lunes, miércoles y viernes) y de dos a tres en sesión extraordinaria (martes, viernes $y$, en ocasiones, sábados).

36 Ibd. "Synodales de la Iglesia de Carthagena», ob.cit.

37 A.C.M. Cód. B-2, f. 74r., 26r., 78r. respectivamente. Obsérvese la alternancia, en letra y en numeración romana, a la hora de constatar el día del mes y el año. A.C.M. Cód. B-2, f.84r y 84v., 99r., 36v.. 74r., respectivamente. 
En lo referente a la estructura textual de las notas-registro no podemos establecer un criterio fijo a la hora de señalar las partes esenciales de cada negocio jurídico escriturado y su orden. No obstante la mayor parte de éstas se ajustan a una tramitación perfectamente reglada. Se inicia el texto con la referencia a la data - expresada anteriormente en epígrafe separado- mediante la fórmula: «Este dicho dia..." o "Este dia..." seguidamente se expresa, bien el nombre de la persona que actúa en representación de otra, individual o colectiva, bien la persona individual o colectivo en representación propia. En el primero de los casos es frecuente la figura u oficio del procurador eclesiástico - cargo en que se concede preferencia a los que anteriormente denominamos «notarios menores» de la audiencia ${ }^{38}$ - aunque en ocasiones observamos la presencia de representantes legos, caso de las minorías étnicas - judios y musulmanes- en estrecha relación con obispo y cabildo ${ }^{39}$. A continuación se recoge la exposición y disposición del acto documentado, concluyendo, en ocasiones, con ciertas cláusulas corroborativas y penales, generalmente pecuniarias y, o eclesiásticas (excomunión, privación de oficio, repulsión, etc.). Como fórmula final aparece en todas ellas la validación, reducida de ordinario a la enumeración de los testigos ${ }^{40} 0$, como es práctica usual en los últimos asentamientos del día, la referencia a estos mediante la fórmula: "Testigos vt supra».

Junto a cada asentamiento y en su margen izquierdo, reservado para la notaciones - Notationes tabularum-, se consigna de forma abreviada, bien mediante epígrafes calificativos referentes a la clase de negocio jurídico escriturado: venta, debdo, arrendamiento, rebeldía, obligación, etc.; bien mediante epígrafes indicativos, expresando, indistintamente, la persona a quien afecta, el negocio y, o el lugar de procedencia: Poder / Gonzalo Díaz / Villena; Condenaçion / Ceruellera.

También son frecuentes las notaciones acerca de la expedición documenta, consignadas a línea tirada al final de la nota-registro". Así bajo el asiento de un contrato de arrendamiento «sobre unas tahullas del obispo en Belchí» fechado en 10 de junio de 1469 , se indica:

«En XXIIII de mayo de LXXIIII a pedimiento de loham Merçd dio su abtoridad el prouisor Alfonso de Ualdeuielso para sacar este abto por

38 Nos aparecen reiteradamente cumpliendo este oficio los nombres de: Alfonso de Santamaría. Juan de Atienza, Alfonso Rodríguez, Alfonso de Baeza y Ferradianes.

39 Vid. MARSILLA DE PASCUAL, F.: «Los judíos y el cabildo catedral en el siglo XV». Miscelánea Medieval Murciana, XV, Murcia, 1989, pp. 55-84. Véase los judios y la justicia capitular, pp. 69-72.

40 Papel en que se concede preferencia a escribanos-notarios, oficios varios, y sobre kodo eclesiásticos y familiares del obispo.

41 BONO HUERTA, J.: Ob. cil.. pp. 26-27. Al contrario que en los castellanos que dichas notaciones se consignan al comienzo de la nota. 
absencia del arcipreste. Ante my Alfonso de Baeça. Testigos: Benito de Villena, capellan; e Ferrando Carrasco e Sancho Gascon, criados.»

Más adelante bajo el asiento del «traspasamiento de unas tahullas del obispo a Juan Merced» fechado en 11 de septiembre de 1469, se constata:

«En Murçia a XXIIII de mayo de LXXIIII ante mi Alonso del Arçe, a pedimiento de loham Merçed se saco este abto con abtoridad del prouisor, Alfonso de Ualdeuielso. Testigos: Bartolome de Villena $e$ Ferrando Carrillo e Sancho Gascon, criados, ecetera» ${ }^{42}$.

Son también numerosas las notaciones sobre el otorgamiento documental, representadas mediante la lineatura de barras paralelas diagonales: / / /; y sobre todo la de barras diagonales cruzadas: $\mathrm{X} X \mathrm{X}$, generalmente reservadas para denotar la cancelación o modificación del negocio escriturado ${ }^{43}$.

Atendiendo a la clasificación de estas notas-registros en base a la escrituración de lo tratado, distinguimos tres tipos: Extensas, Breves y anunciativas ${ }^{44}$. Las extensas, son frecuentes en los asientos referente a: Contrato de compra-venta, Arrendamiento de censos y rentas, etc. ${ }^{45}$ Las breves, son características de los asientos referentes a poderes, cartas de pago, obligación, licencias, etc ${ }^{46}$. En ambos tipos es frecuente encontrarnos la data - fecha crónica y tópica-implícita en el texto de la nota-registro, sobre todo en los contratos de compra y venta y en los otorgamientos de poder, así como en los nombramientos de oficiales de la audiencia.

Por último, a las enunciativas, o aquellas en las que tan sólo se hace referencia al contenido documental, pertenecen la mayor parte de las notas que conforman el presente protocolo. Así por ejemplo, en los casos de:

- Carta Monitoria ${ }^{47}$. "Este dicho dia Alfonso de Baeça en nonbre e commo procurador sostituto de Pedro del Castillo, veçino de Villena, interronpio las

42 A.C.M. Cód. B-2, cit., f.32r, $42 v$, respectivamente.

43 Generalmente se presentan estas notaciones sin indicación alguna al margen por lo que deducirnos que son cancelaciones del asunto tratado.

44 Véase su definición en BONO HUERTAS, J.: «Los Archivos notariales». Ob. cit., p. 21.

45 A.C.M. Cód. B-2, cit., f. $43 r, 43 v, 49 r, 55 r$, etc.

46 lbd. Cód. B-2, cit., f. 78r, 80v, 93v, etc.

47 A.C.M. Cód. B-2, cit., f.73r. C. Monitoria: Despacho de tribunal eclesiástico para obligar a comparecer personalmente a alguno, y deponer lo que supiere en lo que fuese preguntado. También, en ocasiones, recibe el nombre de carta de amonestación. 
moniçiones de vna carta que le fue leyda por Llorenço Gil, veçino de la dicha villa. E pidio treslado e termino para la primera abdiençia. Testigos vt supra.»

\section{- Carta Executoria ${ }^{48}$.}

«Este dicho dia el dicho Alfonso Seuillano pidio execuçión en nonbre de Pasqual Ferrandez, en bienes de Alfonso de Uallibrera, clerigo, e Juan Resalt, fasta en quantia de treynta mill maravedies, etc. El dicho sennor prouisor lo mando fazer, etc. Testigos vt supra.»

- Carta de Rebeldía.

«Este dicho dia Juan Lasso en nonbre de Alfonso Ferrandez de la Madalena, acuso la rebeldia a Pedro Gomez, de Lorca, e pidio carta. E mandose dar. Testigos vt supra.»

- Carta Compulsoria ${ }^{49}$.

«Este dicho dia se presento el dicho Gabriel de Xeres antell dicho sennor prouisor en grado de apelacion, etcetera. E mando dar carta conpulsoria, ecetera. Testigos vt supra.»

Suponemos que toda la documentación aquí referenciada debió recoger en cédulas u hojas separadas, bien intercaladas entre los folios del protocolo -a modo de los hispalenses del $\mathrm{XV}^{50}$ - cosa poco probable en el caso que nos ocupa dada la cuantía de éstas que debería albergar el mismo entre folios; bien en libros matriz destinados a tales fines, donde se agruparía toda la documentación en series y éstas en secciones. Un claro ejemplo de estos libros matriz los encontramos en el Archivo Catedral de Murcia, pertenecientes a la segunda mitad del siglo XVI: Registro de Cartas, Registro de Privilegios, Registro de Censos, Libro de Poderes, traslados de Cartas y Peticiones ${ }^{51}$.

Los tres tipos de redacción —extensa, breve y enunciativa- se nos presenta en forma objetiva.

Para finalizar nos hubiera gustado hacer una breve y ordenada reseña de la tipología documental que emana el presente protocolo, pero dada su amplitud y la conveniencia de no alargar más esta aportación, dejamos su estudio para posteriores trabajos.

48 A.C.M. Cód. B-2, f. 73v.

$49 \mathrm{Ibd}$. Cód. B-2, f. 53r. y 35v. respectivamente.

50 Vid. BONO HUERTAS, J.: «Los Archivos....». Ob. cit., p. 22 (nota).

51 A.C.M. Libro registro de Cartas de 1652. Cód. 206. Libro registro de Privilegios. Cód. 207. Libro registro de Censos. Cód. 207 bis. Libro de Poderes, traslado de cartas y Peticiones, de 1568. Cód. 208 bis. 


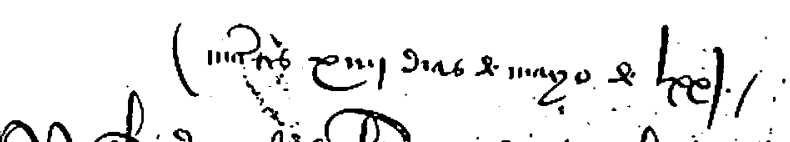

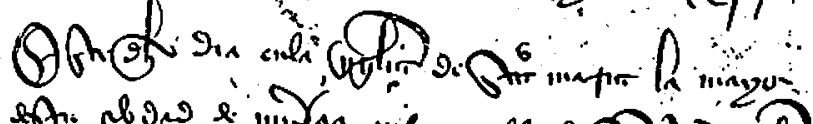

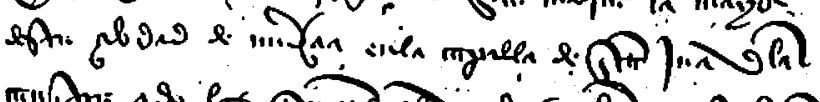

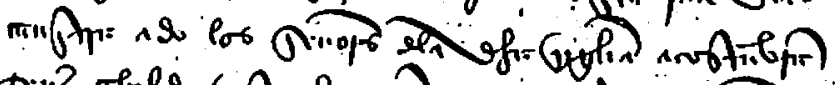

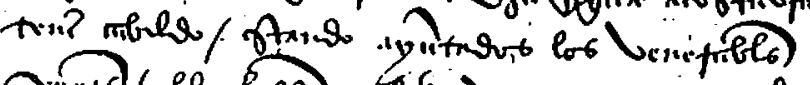

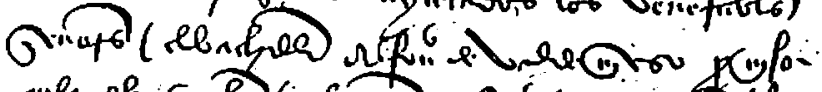

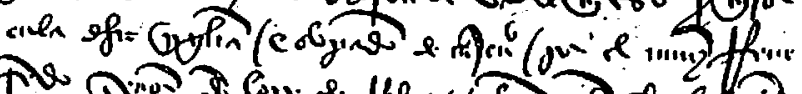

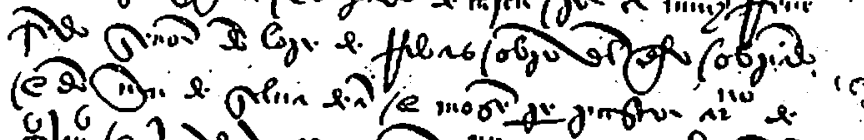

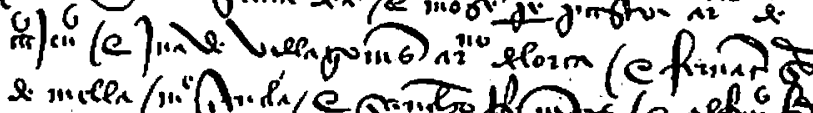

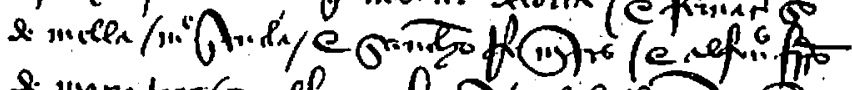

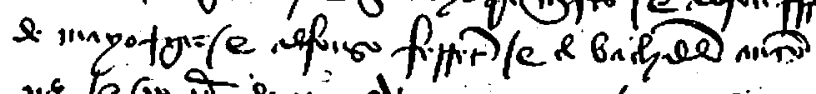

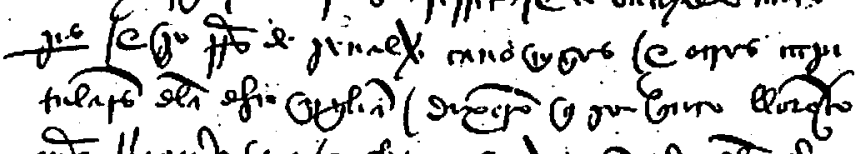

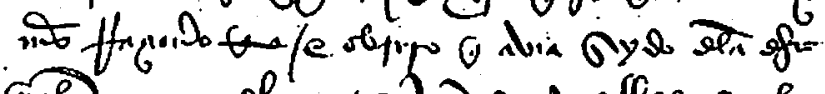

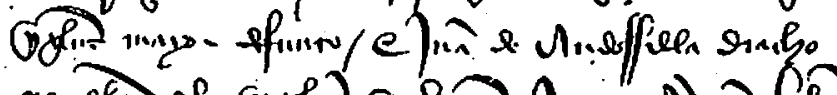

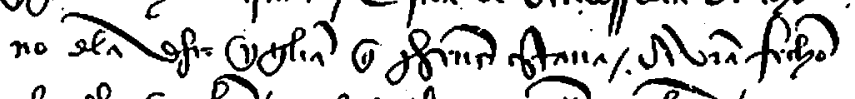

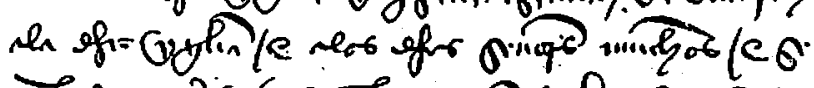

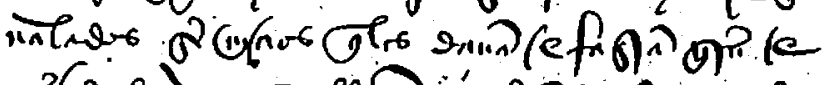

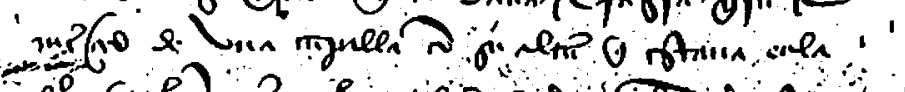

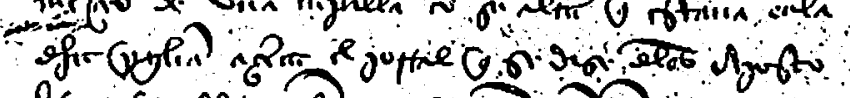

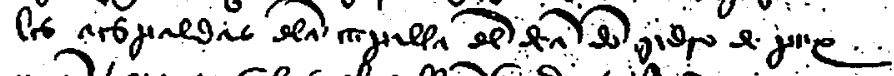

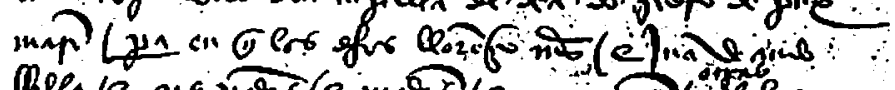

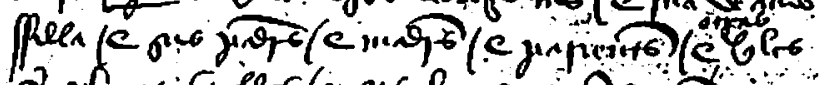

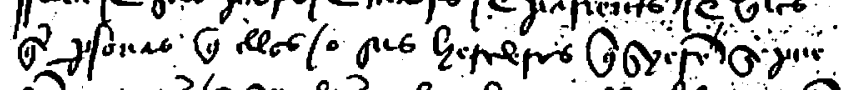

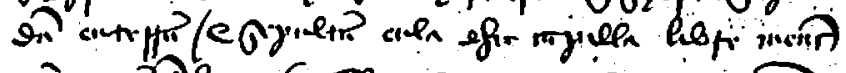

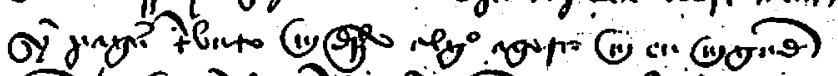

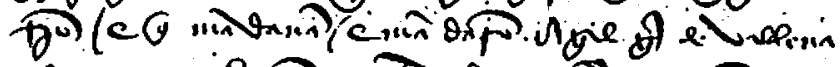

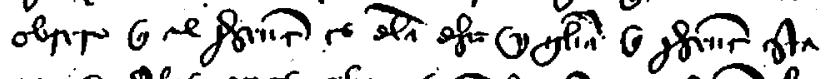

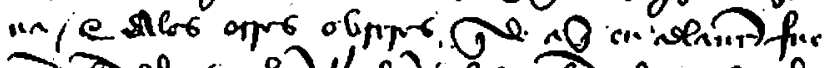

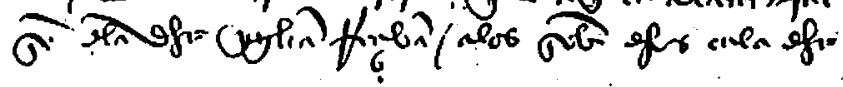

Documento 1. A.C.M. «Protocolo de Juan Sánchez de San Estevan», Cód. B-2, f. 123r123v. 
Dond of

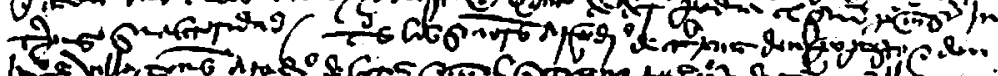

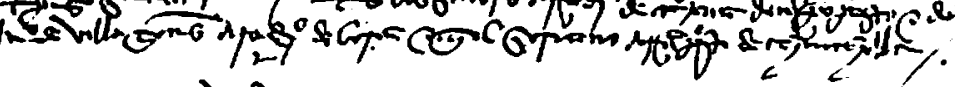

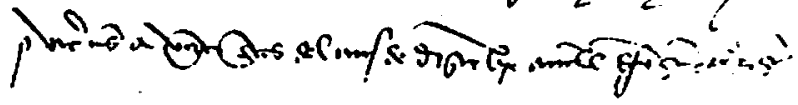

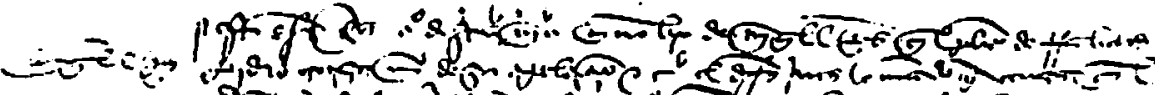

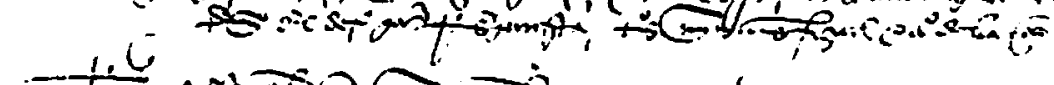

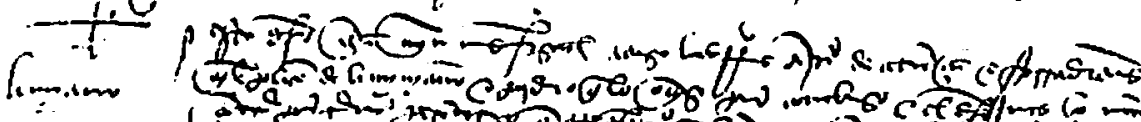
(i)

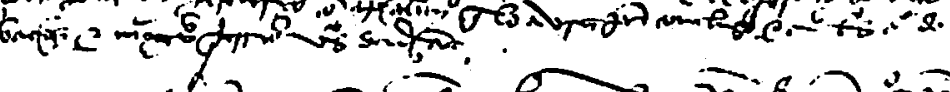

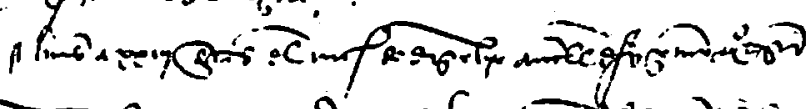

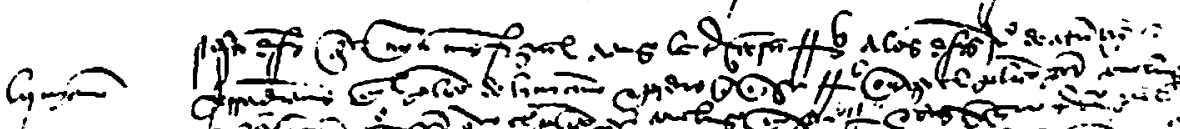

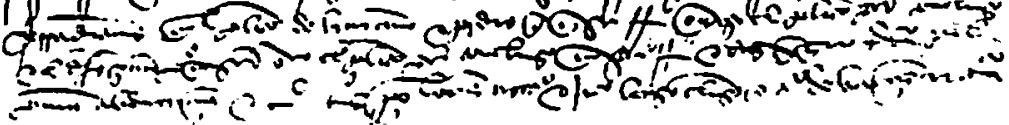

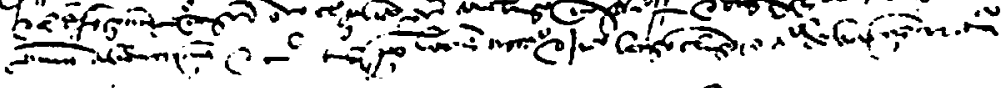

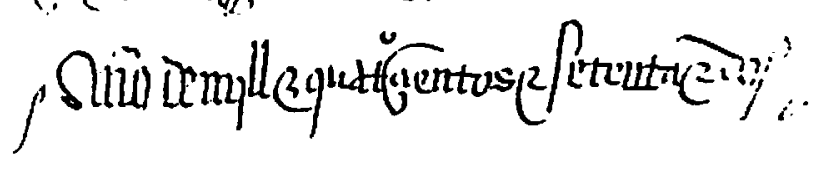

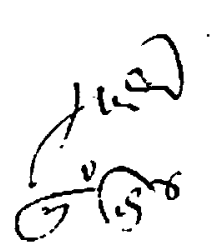

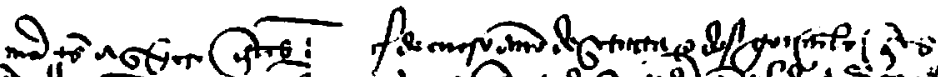

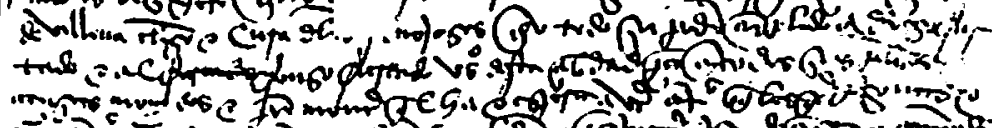
का Dr

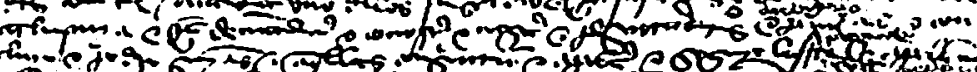
r.

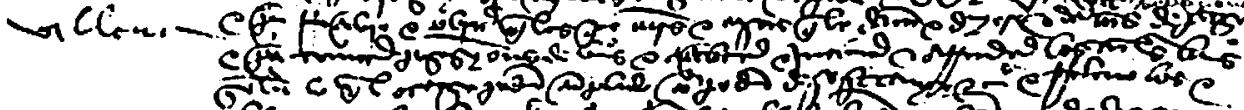

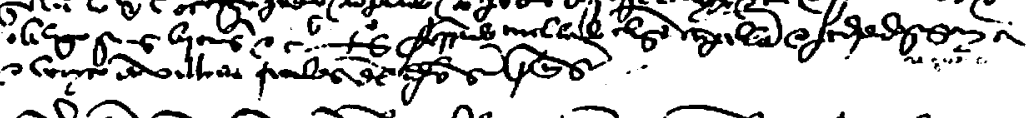

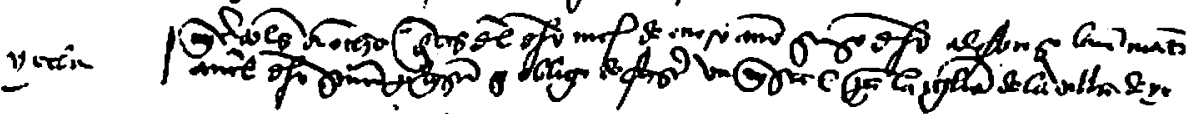

Documento 2. A.C.M. «Protocolo de Juan Sánchez de San Estevan». Cód. B-2, f. 18v. 


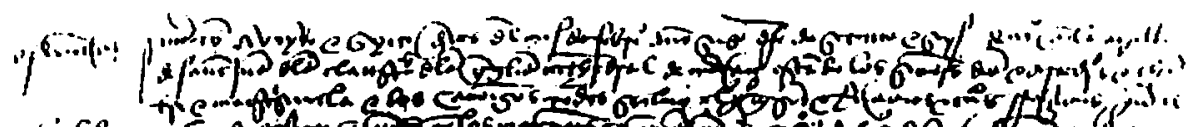

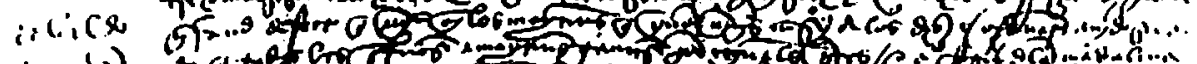
$\therefore 11$ (1)

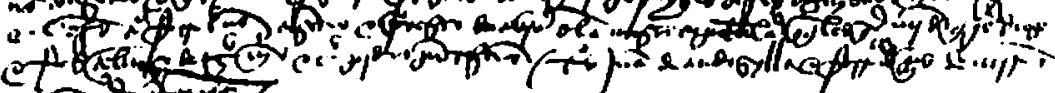

$c$ की की

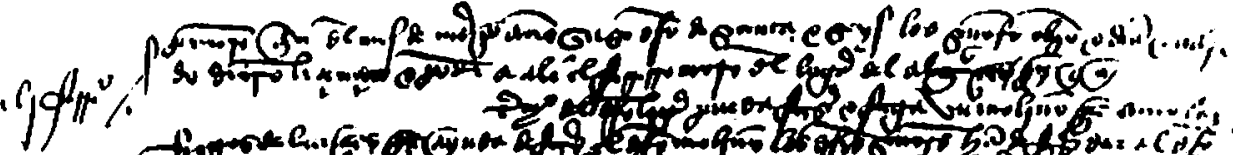

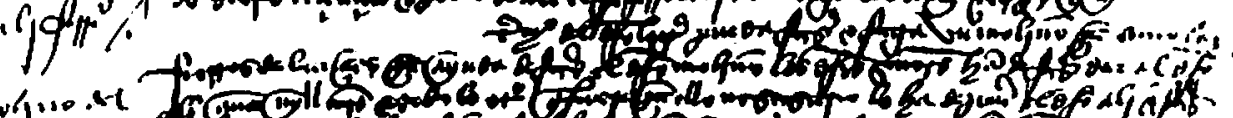

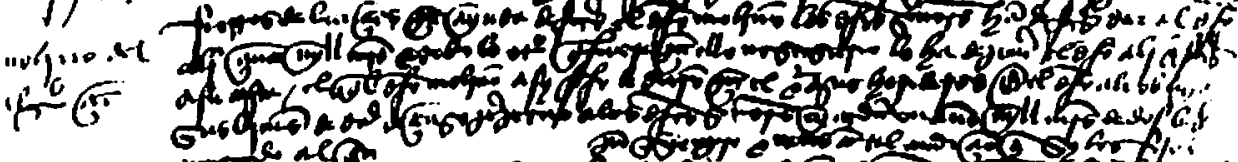
Jya neC

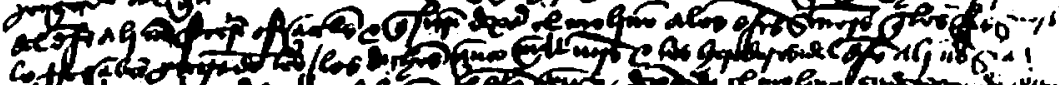

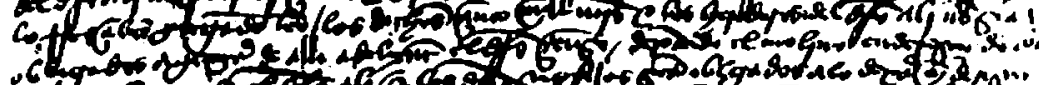

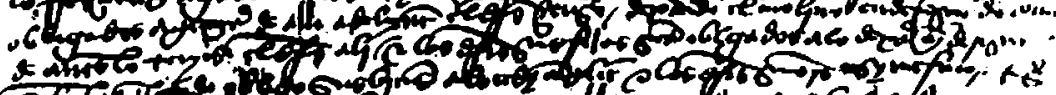

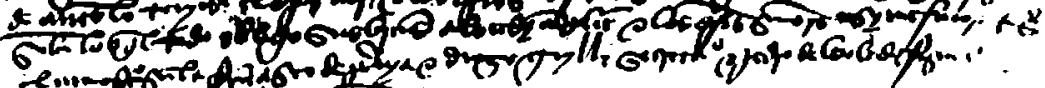

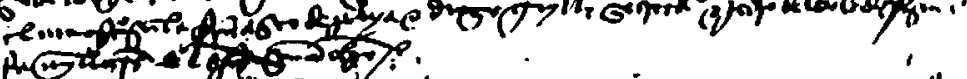

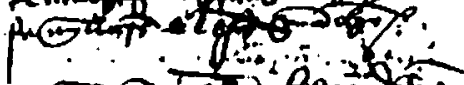

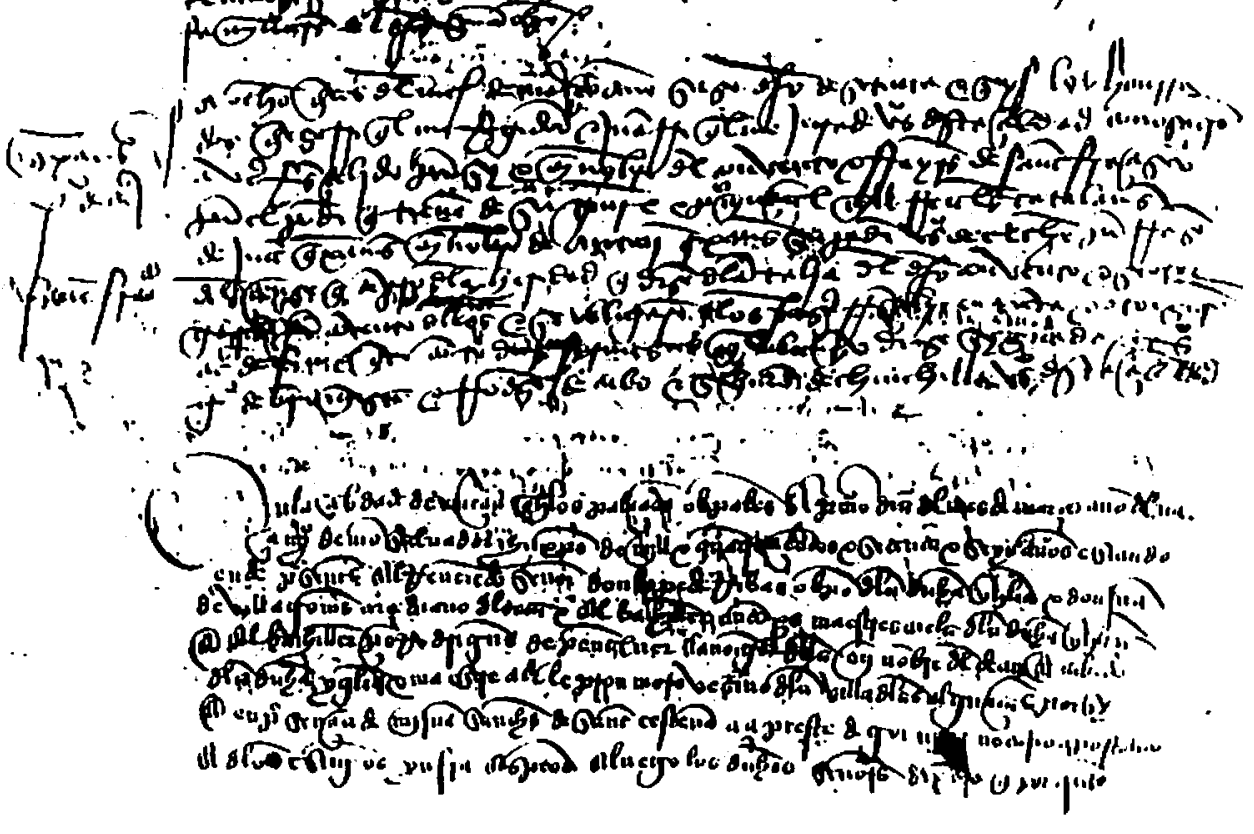

Documento 3. A.C.M. «Protocolo de Juan Sánchez de San Estevan», Cód. B-2, f. 253 r-v. 


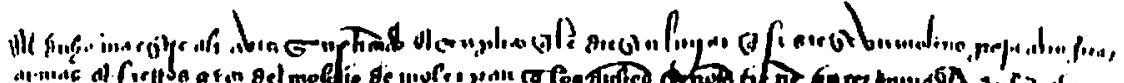

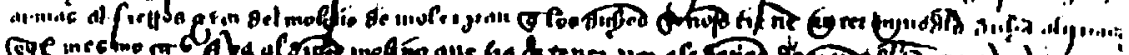

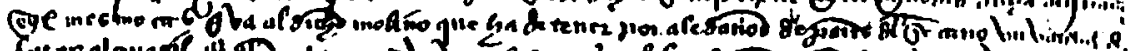

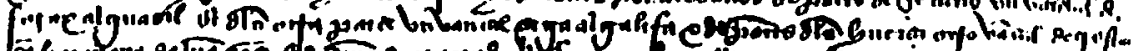

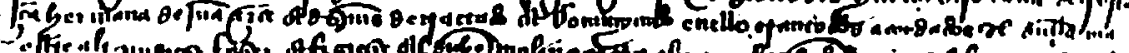

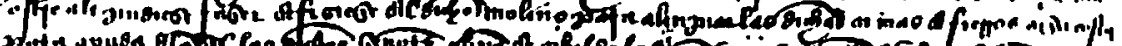

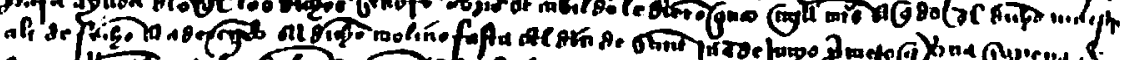

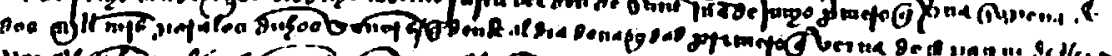

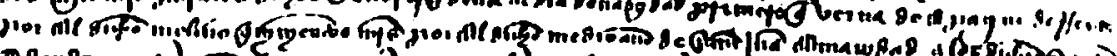

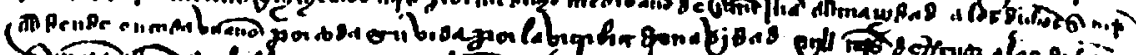

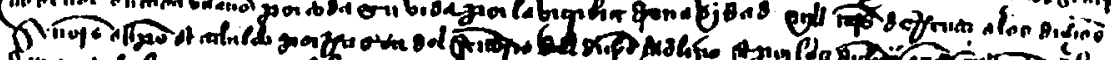

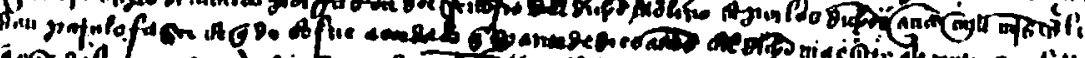

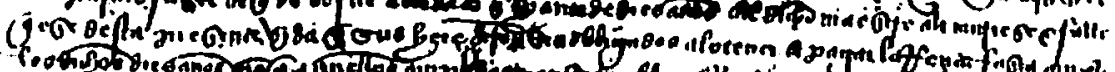

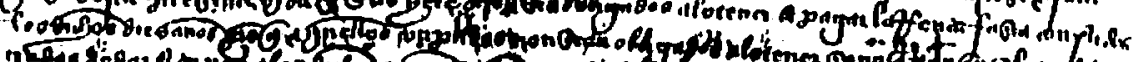

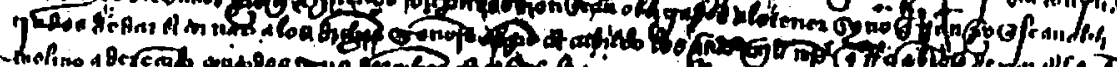

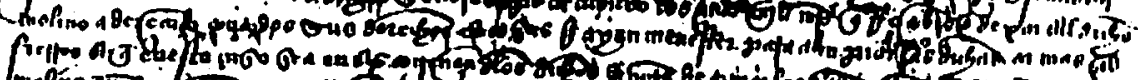
molino gir

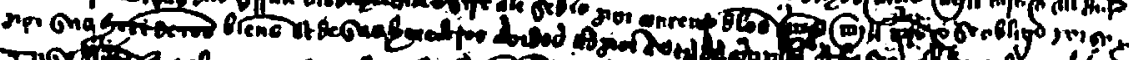

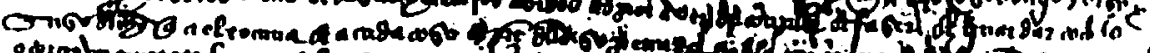

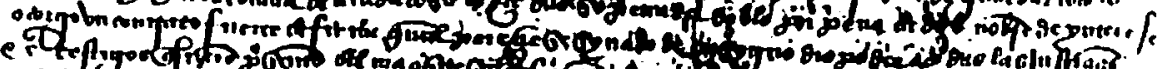

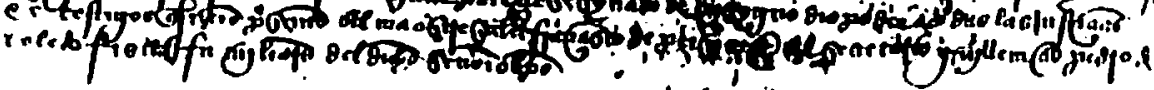

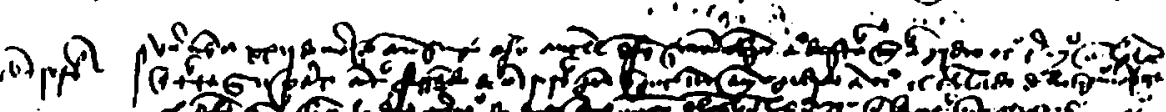

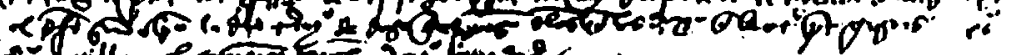

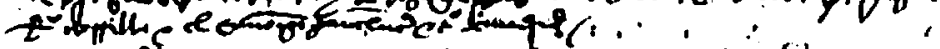

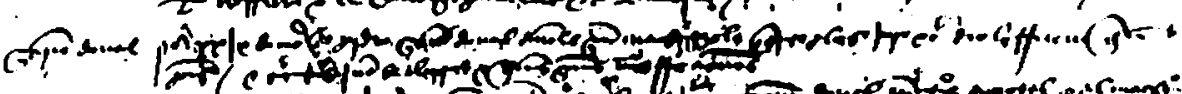

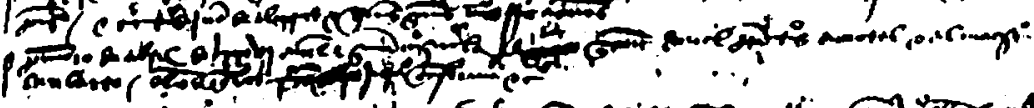

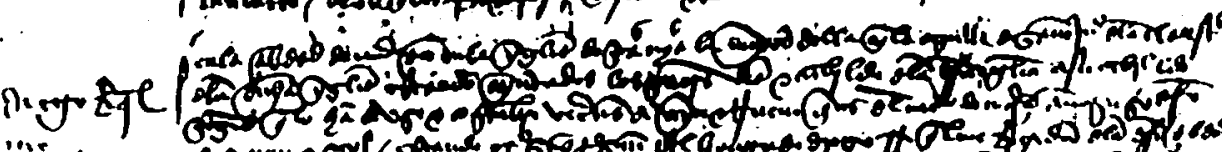
"...

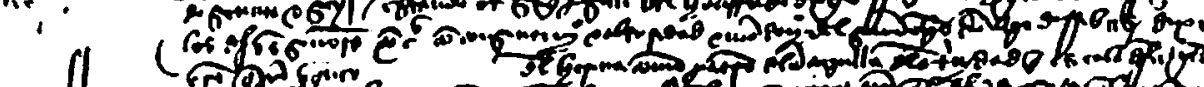

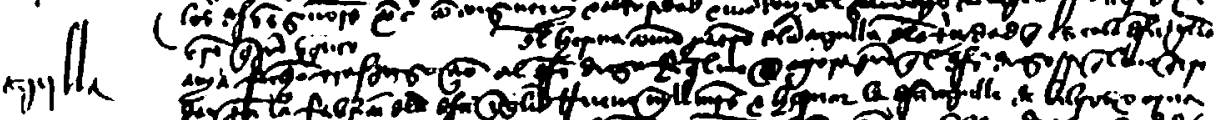

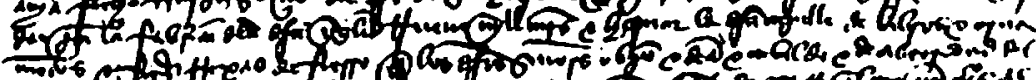

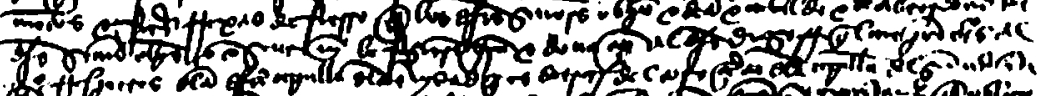

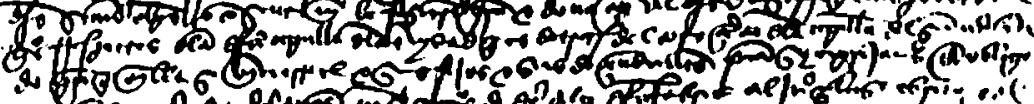

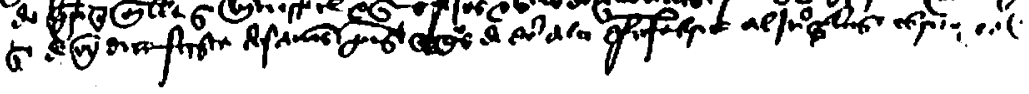

